\title{
Mental health legislation is now a harmful anachronism ${ }^{\dagger}$
}

\author{
George Szmukler and Frank Holloway
}

Two recent developments have served to highlight the contradictory and discriminatury nature of UK mental health legislation, and indeed all 'mental health' acts. These are the Court of Appeal ruling in L. v. Bournewood (1997) and the increasing use of coercion in an attempt to alleviate society's fears of the dangers posed by the mentally ill in the community (Holloway, 1996). At the same time, a third development, the proposal for a Mental Incapacity Act, and the consequent Government Green Paper (Lord Chancellor's Department, 1997) Who Decides provides a framework rendering mental health legislation redundant.

\section{L. v. Bournewood and mental capacity}

In England, under a Court of Appeal judgement (L. v. Bournewood, 1997) an individual cannot be admitted as a voluntary patient to a hospital for treatment of a 'mental disorder' without having the capacity to consent to admission. If the individual lacks such capacity, either a compulsory admission is necessary, if the criteria for admission under the Mental Health Act are met, or the individual must not be admitted at all, even if admission may be in the individual's best interests. This reverses an interpretation of 'informal' admission which has guided practice for almost $\mathbf{4 0}$ years since the Royal Commission on the Law Relating to Mental Illness and Mental Deficiency (1954-1957) expressed the view that mentally ill persons should, whenever possible, be treated informally just as people with physical illness, and that compulsory powers should be reduced to a minimum. There is logic to the Court of Appeal's ruling: where mental health legislation governs the admission to hospital of objecting (and by implication non-consenting patients), those who are incapable of giving consent but are not actively objecting should fall under these provisions. The paradox is that the same person, without the capacity to consent but not objecting. can be admitted to a medical or surgical ward for the treatment of a physical

'See invited commentaries pp. 666-670. editorial 657658, this issue. disorder without special regulation. Put simply, if the person lacks capacity to consent to treatment, and treatment is in the person's 'best interests', it can proceed. On the other hand, the Mental Health Act also permits the non-consensual treatment of people for a mental disorder regardless of whether they have the capacity to make treatment decisions or not. They need only be suffering from a 'mental disorder' of a nature or degree warranting treatment in hospital in the interests of their health or safety. A person with a physical disorder cannot be treated non-consensually if he or she has capacity, even if treatment. if rejected, may result in death.

There is something odd here. Mentally ill and physically ill people who share an incapacity to make treatment decisions are being treated differentially and inconsistently. A disjunction is present between capacity and non-consensual treatment in mental illness, but not physical. The resulting conundrum is even more clearly apparent in some jurisdictions in the US where involuntary commitment to hospital and lack of capacity to consent to treatment are separate issues requiring separate determinations.

\section{Increasing use of coercion}

Following every incident of homicide involving a person with a history of contact with mental health services the media claim that "community care' is failing and endangering the safety of the public. Very likely as a consequence of this, there has been a substantial increase in the use of compulsory admissions to psychiatric hospitals in England and Wales: according to a press release from the Department of Health 29 January 1998 , a $24 \%$ increase in compulsory admissions between 1991-92 and 1994-95. from 20600 to 25600 . The increase has been $30 \%$ for men and $8 \%$ for women, reinforcing the suggestion that it is a response to an increased demand from the community for protection against the 'dangerously insane', men stereotypically and prejudicially being seen as more threatening (especially Black men). There has been a parallel rise in the number of patients who offend being detained in conditions of 
medium security. At the same time there are frequent calls for 'community treatment orders' permitting the forced treatment of patients in the community, or recall to hospital at an early stage of relapse. Also ever-present is a tendency to attempt to label apparently 'disturbed' dangerous persons, not considered by psychiatrists to be mentally ill, as suffering from a mental disorder so they may be covered by the provisions of the Mental Health Act and detained in hospital to prevent offending. The latest example concerns apparently dangerous paedophiles following release from prison.

These movements are only possible because we permit a form of preventative detention of the mentally ill. Indeed the Mental Health Act provides the only legal means of preventative detention. Why should different rules govern society's response to dangerous mentally disordered persons compared to dangerous nonmentally disordered persons?

\section{Specific mental health legislation discriminates against those with a mental disorder}

A case that mental health legislation discriminates against patients with mental illness and reinforces prejudice against them has been put with great clarity and force by Campbell \& Heginbotham (1991), Campbell (1994) and Rosenman (1994). The Bournewood ruling and the use of the Mental Health Act to detain mentally ill people in hospital for the protection of others provide further evidence they are right.

The message is as follows: though ill, those with a mental disorder are somehow different. That is why they require separate legislation. They may be treated against their will irrespective of whether they have the capacity to consent to treatment. This suggests a pervasive and disturbing notion that 'mental' patients somehow are incapable of possessing a full degree of autonomy: mental disorder automatically diminishes the sufferer; he or she is not a complete 'person'. There is also something different about the dangerousness posed by persons with a mental illness, such that preventative detention through the agency of mental health legislation is acceptable for them. but only for them. It is rejected for others because of the potential for abuse, but is apparently warranted for the mentally ill because dangerousness is somehow inseparable from mental illness. We do not insist on evidence (non-existent) that dangerousness is more predictable in the mentally ill.

These messages about mental illness, subtly, and couched in a rhetoric of care, reinforce damaging stereotypes which act against our acceptance of people with mental illness as full citizens. So pervasive are our assumptions, that one does not recognise them until the possibility of a world without specific mental health legislation is entertained.

\section{When should someone be treated against his or her will?}

Let us go back to first principles. Paternalistic interventions are accepted under certain circumstances for those without the mental capacity to make reasonable judgements about their health needs. The necessary elements are a demonstrable absence of capacity to make treatment decisions and a justification of the treatment in the patient's 'best interests'. These are well discussed in the recent Law Commission report (1993), Mental Incapacity.

There is no logical reason to discriminate between mental incapacity occasioned by mental disorder and physical disorder. Many readers will by now have retorted that the Mental Health Act ensures that people treated for a mental disorder under compulsion are protected by an extensive set of regulations. These safeguards do not at present apply in this country to people without capacity suffering from physical disorders, and it was in part as a result of the recognition of the need for greater controls that the Law Commission embarked on its considerations of the implications of mental incapacity. Historically, the discrepancy between protections for the treatment of mental disorder and physical disorder probably arises from treatments for the former having been seen as dubious and possibly resembling punishment more closely than treatment (e.g. electroconvulsive therapy, psychosurgery). But clearly if people with mental illness warrant protection against poor or inappropriate treatment, so indeed do those physically ill persons without the capacity to look after themselves. The surgeon's knife poses at least as great a threat as the psychiatrist's antipsychotic medication.

\section{A solution for our times}

It is here that the third major recent development has shown a way forward. Until now there have not been satisfactory protections for physically ill persons with mental incapacity. Doctors could act if the person lacked capacity and treatment was in his or her best interests, this being defined according to the 'Bolam' principles what a recognised body of medical opinion considers appropriate. There is no process of review. However, the Law Commission report (1995), Mental Incapacity, provides a clear framework for the treatment of patients who lack capacity. While the Law Commission explicitly 
avoided the question of mental illness and the relationship of capacity to the Mental Health Act, we do not see any reason why its recommendations should not apply as well to the mentally as the physically ill, and why all groups of patients should not be adequately protected within this framework.

The Law Commission has provided workable definitions of 'incapacity' and 'best interests' (see Appendix). A range of methods for ensuring the proper treatment of patients with incapacity is presented. These include advance directives, continuing powers of attorney (as a method of substituted decision-making), second opinions for specified or controversial treatments, court appointed managers for some procedures or situations and a judicial role for appeals and for treating objecting (rather than non-resisting) patients. In addition to needing to meet the test of 'best interests' each of these mechanisms has its associated protections. To this range of options may also be added advocacy, a useful means of representing the needs of patients who have difficulties in expressing their wishes. The Law Commission also recognises the value of a Code of Practice where provisions can be stipulated in greater detail and where they can evolve over time.

Judicial bodies for treating objecting patients need not be very 'court-like' or adversarial. They could, for example, function in a similar way to mental health review tribunals. Incapacity legislation of the type proposed by the Law Commission presents a framework for all paternalistic interventions for ill persons lacking mental capacity. These should include those suffering from mental disorders. Indeed the flexible range of provisions is very suitable for treatment in the community rather than hospital settings. It has been argued that advance directives, for example, present an autonomybased solution to non-consensual treatment in the community (Halpern \& Szmukler, 1997).

\section{Protection of others}

An Incapacity Act along the lines discussed above would not however cover the protection of others', which is confusingly rolled into the Mental Health Act together with the protection of the health or safety of the patient. We see no justification for treating dangerousness in the mentally ill any differently to dangerousness in others. It is not more predictable in this group (compare with habitual domestic violence associated with alcohol, for example), and even if it were, would still not justify a lower threshold for detention. The treatability of the person is also not a justification: groups of non-mentally ill dangerous persons might respond just as well to psychological or social interventions. In any case, treatment-resistant mentally ill people continue to be detained despite this, usually for even longer.

The justification for non-consensual treatment for dangerousness is not paternalistic. A separate framework is necessary-some kind of dangerousness legislation. (This is excellently discussed by Campbell \& Heginbotham (1991).) Since most dangerous people in society are not mentally ill, if we truly wish to protect the community from such risks, logic would dictate generic legislation. Since a form of preventative detention may ensue, decisions need to be made according to due process with exacting safeguards. A judicial body of some kind, advised by appropriate experts, needs to decide that according to a specified test, a person presents a level of risk of harm to others that cannot be tolerated. Disposals may vary. If the person is mentally ill, and treatment will eliminate or reduce the risk, a psychiatric disposal may be appropriate. If the person is not ill, but dangerous, another kind of disposal will be appropriate, perhaps including imprisonment. Psychiatrists in such a system will not be required both to detain and treat people; they will be required only to treat people detained by a court. This will reduce the explicit social control function which mental health professionals now find ethically compromising.

Generic dangerousness legislation and explicit preventative detention will meet with resistance, and we are not necessarily advocating it. Lawyers will argue that it is wrong to detain those who have not committed an offence (presumably unless they are mentally ill). Our society is preoccupied with danger and the quest for safety. A public debate seems warranted. If preventative detention is deemed unacceptable. so should it be for those with a mental illness as for the rest of us. If it is deemed acceptable but with narrow tests and tight controls, then it will protect the rights of the mentally ill who happen to be dangerous just as much as the nonmentally ill. By making laws generic, applying to everyone rather than only a defined minority with a mental disorder, we ensure that we will look more gravely at how they are applied and whether individuals' rights are being abused.

\section{Conclusions}

We have outlined how mental health legislation reinforces discriminatory stereotypes. It implies that mental illness is different, and inextricably linked with incompetence and dangerousness. Possible new legislation governing 'mental incapacity' provides an opportunity to move towards a more rational approach to nonconsensual treatment for all ill persons. We 
predict significant benefits to people with mental illness. Stereotypes with their associated prejudice will be reduced, there will be fewer inappropriate admissions to hospital, people will seek treatment at an earlier stage fearing less stigma and coercion, and staff morale will improve since they will see themselves as therapists and not as social agents. Indeed, dismantling mental health legislation may be the single most important action we can take to finally give equal rights to persons with mental illness and to eliminate stigma.

\section{Appendix Proposed definitions in Law Commission report (1995), Mental Incapacity, and Green Paper: Who Decides? (1997)}

\section{'Incapacity'}

A person is without capacity if at the material time he or she is: (a) unable by reason of mental disability to make a decision on the matter in question, or (b) unable to communicate a decision on that matter because he or she is unconscious or for any other reason.

\section{'Mental disability'}

Any disability or disorder of the mind or brain, whether permanent or temporary, which results in an impairment or disturbance of mental functioning.

\section{'Unable to make a decision by reason of mental disability'}

The person is (a) unable to understand or retain the information relevant to the decision. including information about the reasonably foreseeable consequences of deciding one way or another or failing to make the decision, or (b) unable to make a decision based on such information (for example, some people may be unable to exert their will, whether because of delusions or compulsions, or because of susceptibility to influence, or any other reason connected with their disability).

\section{'Best interests'}

Anything done for, and any decision made on behalf of, a person without capacity should be done or made in the best interest of that person.
Guidance for deciding what is in the person's 'best interests'

Regard should be given to the following factors:

(a) the ascertainable past and present wishes and feelings of the person concerned, and the factors that person would consider if able to do so;

(b) the need to permit and encourage the person to participate or improve his or her ability to participate as fully as possible in anything done for and any decision affecting him or her:

(c) the views of other persons whom it is appropriate and practical to consult about the person's wishes and feelings and what would be in his or her best interests; and

(d) whether the purpose for which any action or decision is required can be as effectively achieved in a manner less restrictive of the person's freedom of action.

\section{References}

CAMPBELL. T. (1994) Mental health law: institutionalised discrimination. Australian and New Zealand Journal of Psychiatry, 28, 554-559.

- \& Heginbotham. C. (1991) Mental Illness: Prejudice. Discrimination and the Law. Brookfield. VT: Dartmouth.

HALPERN, A. \& SZMUKLER, G (1997) Psychiatric advance directives: reconciling autonomy and non-consensual treatment. Psychiatric Bulletin, 21, 323-327.

Holloway, F. (1996) Community psychiatric care: from libertarianism to coercion. "Moral Panic" and mental health policy in Britain. Health Care Analysis. 4. 235-243.

LAW CoMmission (1995) Mental Incapacity (Law Commission Report No. 231). London: HMSO.

LORD CHANCELLOR'S DEPARTMENT (1997) Who Decides? Making Decisions on Behalf of Mentally Incapacitated Adults. London: HMSO.

Rosenman, S. (1994) Mental health law: an idea whose time has passed. Australian and New Zealand Journal of Psychiatry, 28, 560-565.

L. v. Bournewood Community and Mental Health Trust ex parte L. (1998) 1 All ER 634.

*George Szmukler, Medical Director, and Frank Holloway. Consultant Psychiatrist. Bethlem and Maudsley NHS Trust, Maudsley Hospital. Denmark Hill, London SE5 8AZ

*Correspondence 